\title{
Synergistic Effect of Combination Interventions for Methicillin-resistant Staphylococcus aureus Transmission Control in Nursing Homes: A Computation Modelling Evaluation with Heterogeneous Contact Mixing
}

\section{Arthur Tang}

Sungkyunkwan University https://orcid.org/0000-0002-6655-6883

Kin On Kwok ( $\nabla$ kkokwok@cuhk.edu.hk)

The Chinese University of Hong Kong

\section{Vivian Wan In Wei}

Chinese University of Hong Kong

Hong Chen

Centre for Health Protection, Hong Kong

\section{Woo-Hyun Park}

Sungkyunkwan University - Suwon Campus

\section{Samuel Yeung Shan Wong}

Chinese University of Hong Kong

Wilson Tam

National University of Singapore

\section{Research}

Keywords: Antimicrobial resistance, Methicillin-Resistant Staphylococcus aureus transmission, Simulation and modelling, Nursing home, Interventions

Posted Date: August 25th, 2020

DOI: https://doi.org/10.21203/rs.3.rs-60219/v1

License: (c) (1) This work is licensed under a Creative Commons Attribution 4.0 International License. Read Full License

Version of Record: A version of this preprint was published at Antibiotics on February 24th, 2021. See the Loading [MathJax]/jax/output/CommonHTML/jax.js //antibiotics10030227. 


\section{Abstract \\ Background}

The endemic threat of Methicillin-Resistant Staphylococcus aureus (MRSA) in nursing homes pose a serious and escalating challenge to public health administration in infection control. Nursing homes are considered as major reservoirs for MRSA colonization, with considerable high levels of colonization prevalence.

\section{Aim}

Direct contact is the major transmission mode of MRSA colonization. This study employed a computation model to evaluate the effect of 3 intervention scenarios on MRSA colonization prevalence rate in nursing homes.

\section{Methods}

Simulations were conducted using a deterministic compartmental model featuring heterogeneous contact matrix between residents and health-care workers (HCWs). Contact parameters were derived from a nursing home survey. Three intervention scenarios were simulated: (1) hand-hygiene compliance by HCWs, (2) screening-and-isolation upon admission, and (3) implementing both interventions at the same time.

\section{Results}

For every $10 \%$ reduction in average contamination duration in HCWs, the estimated average reduction in prevalence rate is 1.29 percentage point compared with the prevalence rate before the intervention was implemented. Screening-and-isolation intervention results in an average reduction of 19.04 percentage point in prevalence rate $(\mathrm{s} . \mathrm{d} .=1.58 ; 95 \% \mathrm{Cl}=18.90-19.18)$ compared with the prevalence rate before the intervention was implemented. In intervention scenario 3 , synergistic effects were observed when implementing hand-hygiene compliance by HCWs and screening-and-isolation together.

\section{Conclusion}

Our results provide quantitative data for nursing home administrators in interventions planning, design, adjustment, effect estimation and comparison.

\section{Background}


Antimicrobial resistance (AMR) has become one of the major pressing public health threats and challenges globally. Antibiotics are widely used to combat life-threatening bacterial diseases. However, the imprudent use of antibiotics contributes to resistance among pathogenic microorganisms which in turn threatens the effective treatment of bacterial, parasitic, viral and fungal infection. MethicillinResistant Staphylococcus aureus (MRSA) is a multi-drug resistant strain of Staphylococcus aureus, and is regarded as one of the major AMR pathogens. Among the 18 drug-resistant threats identified by the United States Centers for Disease Control and Prevention, MRSA is regarded as a serious threat, where patients in healthcare settings frequently have severe or potentially life-threatening infections [1].

MRSA is commonly associated with the morbidity and mortality among elderly individuals. The overall incidence rates of MRSA infection among elderly individuals were consistently highest among other age groups globally [2-4]. Its strains were commonly identified in health care facilities, especially in nursing homes [5] which are considered as major reservoirs for MRSA [6]. MRSA was endemic at high levels in nursing homes $[7,8]$. Previous research works reported that MRSA colonization prevalence rate in nursing homes can be as high as $52 \%$ in the United States [9-11], significantly higher than that of $1.5 \%$ in the general population. Residents in nursing homes were shown to carry MRSA for a considerably long period of time: asymptomatic colonization could last for more than 3 years $[12,13]$.

The endemic threat of MRSA in nursing homes along with the trend in global population aging pose a serious and escalating challenge to public health administration in infection control. Compared to acute care hospital settings, little was known about the epidemiology of MRSA in nursing homes. A primary effort in MRSA control of nursing homes is to drive down the endemic prevalence rate. Two key MRSA infection control measures for nursing-home are hand-hygiene by healthcare workers (HCWs) and screening followed by isolation for residents upon their admissions. One of the concerns for nursing homes administration is how to evaluate effectiveness among different interventions in reducing the carriage prevalence rate. As natural experiment studying infectious diseases transmission is neither possible nor ethical, computational modelling becomes an essential tool to simulate how infectious diseases progress and to evaluate the impact of infection control policies with different intervention implementations.

The major transmission mode of MRSA infections is through direct contact with wounds, discharge and soiled areas [14]. A recent systematic review on mathematical modelling of antimicrobial resistance summarizes computation models simulating MRSA transmission in nursing home settings [15]. The population in models were mostly homogeneous except one modelling study in nursing home setting explicit represents the contact between residents and healthcare workers (HCWs) [6]. Our study further extended this computation model to evaluate the effect of two interventions to MRSA colonization prevalence: (1) hand-hygiene compliance by HCWs and (2) screening-and-isolation upon admission. We used the aggregate social contact information among residents and staff obtained in the previous contact survey [16] and demographics of nursing homes as inputs of our simulation model. We also explored the potential synergistic effect of bundling the two interventions. 


\section{Methodology}

The Computational Model

A two-level compartmental model with deterministic framework was employed. Nursing home residents are considered as hosts of MRSA, and HCWs are considered as transmission vectors. Residents are categorized into two mutually exclusive states: (a) uncolonized or (b) colonized; whereas HCWs are categorized into two mutually exclusive states: (c) contaminated or (d) uncontaminated. The model features the residents' admission from community/hospital and discharge/death of the residents who are susceptible and colonized. Different routes of transmission were taken into account via the close contact among HCWs and residents: (i) HCWs-residents contacts, (ii) residents-residents contacts, and (iii) residents-HCWs contacts. Two types of transmission were defined in the model: Colonization and Contamination. MRSA can be transmitted to uncolonized residents by contact made with colonized residents or contaminated HCWs. Uncontaminated HCWs can be contaminated by contact made with colonized residents. Schematic of the transmission model is illustrated in Fig. 1.

The model is described with the following set of nonlinear differential equations:

$$
\begin{gathered}
\frac{d U(t)}{d t}=-\frac{\beta_{r-r} U(t) C(t)}{N_{r}}-\frac{\beta_{h-r} U(t) H_{C}(t)}{N_{h}}+\omega C(t)+(1-\lambda) \Lambda-\gamma_{u} U(t) \\
\frac{d C(t)}{d t}=\frac{\beta_{r-r} U(t) C(t)}{N_{r}}+\frac{\beta_{h-r} U(t) H_{C}(t)}{N_{h}}-\omega C(t)+\lambda \Lambda-\gamma_{C} C(t) \\
\frac{d H(t)}{d t}=-\frac{\beta_{r-h} H(t) C(t)}{N_{r}}-\frac{\beta_{h-h} H(t) H_{C}(t)}{N_{h}}+\mu H_{C}(t) \\
\frac{d H_{C}(t)}{d t}=\frac{\beta_{r-h} H(t) C(t)}{N_{r}}-\mu H_{C}(t)
\end{gathered}
$$

where $U(t), C(t), H(t)$ and $H_{c}(t)$ denoted the population size of uncolonized-residents, colonized-residents, uncontaminated-HCWs and contaminated-HCWs respectively in a nursing home at time t. $1 / \mu$ denoted the mean duration of contamination while $1 / \omega$ denoted the mean duration of colonization. $N_{r}$ denoted the population of residents and $N_{h}$ denoted the population of healthcare-workers, where $N_{r}=U(t)+C(t)$ and $N_{h}=H(t)+H_{c}(t)$.

The average length of stay of colonized residents and uncolonized residents are denoted by $\gamma_{\mathrm{u}}$ and $\gamma_{\mathrm{c}}$ respectively. Residents are admitted at the rate of $\Lambda$, and the probability of admitted residents being colonized is $\lambda$. It is assumed that the number of residents and HCWs remain constant, and the occupancy rate is $100 \%$. Therefore, residential admission rate equals to residents discharge rate; i.e. $\Lambda=\gamma_{\mathrm{u}} \mathrm{U}+\gamma_{\mathrm{c}} \mathrm{C}$. 
Three transmission rates were defined in the model. $\beta_{r-r}$ and $\beta_{h-r}$ denoted the residents-to-residents transmission rate and HCWs-to-residents transmission rate respectively, whereas $\beta_{r-h}$ denoted the residents-to-HCWs transmission rate. The values of these three transmission rates were defined as the estimated number of contacts multiplied by the transmission probability via contact, as summarized in Table $1 \mathrm{a}$ and $1 \mathrm{~b}$. Three types of contact and transmission probability were defined. $\mathrm{a}_{\mathrm{r}-\mathrm{r}}, \mathrm{a}_{\mathrm{r}-\mathrm{h}}$ and $\mathrm{a}_{\mathrm{h}-\mathrm{r}}$ denote the average number of residents-to-residents contact, residents-to-HCWs contact and HCWs-toresidents contact respectively. $\mathrm{p}_{\mathrm{r}-\mathrm{r}}, \mathrm{p}_{\mathrm{r}-\mathrm{h}}$ and $\mathrm{p}_{\mathrm{h}-\mathrm{r}}$ denote the transmission probability via residents-toresidents contact, residents-to-HCWs contact and HCWs-to-residents contact respectively.

Table 1

a. The three transmission rates defined in the computational model.

\begin{tabular}{|lll|}
\hline Description & Symbol & Value \\
\hline Residents-to-residents transmission rate & $\beta_{r-r}$ & $a_{r-r} p_{r-r}$ \\
\hline HCWs-to-residents transmission rate & $\beta_{h-r}$ & $a_{h-r} p_{h-r}$ \\
\hline Residents-to-HCWs transmission rate & $\beta_{r-h}$ & $a_{r-h} p_{r-h}$ \\
\hline
\end{tabular}

Table 1

b. The six parameters used in the three transmission rates.

\begin{tabular}{|ll|}
\hline Description & Symbol \\
\hline Average number of residents-to-residents contact & $\mathrm{a}_{\mathrm{r}-\mathrm{r}}$ \\
\hline Average number of HCWs-to-residents contact & $\mathrm{a}_{\mathrm{h}-\mathrm{r}}$ \\
\hline Average number of residents-to-HCWs contact & $\mathrm{a}_{\mathrm{r}-\mathrm{h}}$ \\
\hline Transmission probability via residents-to-residents contact & $\mathrm{p}_{\mathrm{r}-\mathrm{r}}$ \\
\hline Transmission probability via HCWs-to-residents contact & $\mathrm{p}_{\mathrm{h}-\mathrm{r}}$ \\
\hline Transmission probability via residents-to-HCWs contact & $\mathrm{p}_{\mathrm{r}-\mathrm{h}}$ \\
\hline
\end{tabular}

Parameterization

Parameters Identification

15 parameters were incorporated in the model. Values of 12 of the 14 parameters were identified in the parameterization process. Values of 2 parameters cannot be identified and were estimated. Table 2 summarizes the 14 parameters. 
Table 2

List of 12 of the 14 parameter values used in the computational model.

\begin{tabular}{|llll|}
\hline Description & Symbol & Value & Reference \\
\hline Number of residents & $\mathrm{N}_{\mathrm{r}}$ & 75.10 & {$[16]$} \\
\hline Number of HCWs & $\mathrm{N}_{\mathrm{hcw}}$ & 8.61 & {$[16]$} \\
\hline Probability of admission of colonized residents & $\wedge$ & $15.8 \%$ & {$[17]$} \\
\hline Average duration of colonization (days) & $1 / \omega$ & 268.8 & {$[18]$} \\
\hline Average length of stay for uncolonized residents (days) & $1 / \mathrm{Y}_{\mathrm{u}}$ & $233.89 *$ & {$[17,19]$} \\
\hline Average length of stay for colonized residents (days) & $1 / \mathrm{Y}_{\mathrm{c}}$ & $233.89 *$ & {$[17,19]$} \\
\hline Average contamination duration (hours) & $1 / \mu$ & $4.1 *$ & {$[16]$} \\
\hline Average number of residents-to-residents contact & $\mathrm{a}_{\mathrm{r}-\mathrm{r}}$ & 0.2 & {$[16]$} \\
\hline Average number of HCWs-to-residents contact & $\mathrm{a}_{\mathrm{h}-\mathrm{r}}$ & 1.2 & {$[16]$} \\
\hline Average number of residents-to-HCWs contact & $\mathrm{a}_{\mathrm{r}-\mathrm{h}}$ & 12.7 & {$[16]$} \\
\hline Average number of HCWs-to-HCWs contact & $\mathrm{a}_{\mathrm{h}-\mathrm{h}}$ & 0.6 & {$[16]$} \\
\hline Transmission probability via residents-to-residents contact & $\mathrm{p}_{\mathrm{r}-\mathrm{r}}$ & Not identified & \\
\hline Transmission probability via HCWs-to-residents contact & $\mathrm{p}_{\mathrm{h}-\mathrm{r}}$ & Not identified & \\
\hline Transmission probability via residents-to-HCWs contact & $\mathrm{p}_{\mathrm{r}-\mathrm{h}}$ & $20 \%$ & {$[20]$} \\
\hline
\end{tabular}

* Average length of stay for uncolonized residents and average length of stay for colonized residents were calculated based on data presented in Kwok et al. [19]. Average contamination duration was calculated based on data presented in Kwok et al. [16]. Detail of calculations of these three parameters is included in Supplementary Material S1.

\section{Parameter Estimation}

No best estimates of two key parameters were identified from prior study: (a) transmission probability via residents-to-residents contact and (b) transmission probability via HCWs-to-residents contact. We estimated these two parameters by fitting the mathematical transmission model to the prevalence data. Four MRSA point-prevalence rates and their $95 \%$ confidence interval (Cl) of nursing homes in Hong Kong were identified from prior studies (Table 3) [17, 21-23]. We denoted the date of these four pointprevalence rates as Day 1, Day 108, Day 1600 and Day 2239. 
Table 3

Point-prevalence of MRSA in Hong Kong nursing homes.

\begin{tabular}{|c|c|c|c|c|c|}
\hline Study period & $\begin{array}{l}\text { Mid-date of study } \\
\text { period }\end{array}$ & $\begin{array}{l}\text { Day } \\
\text { count }\end{array}$ & Prevalence & $95 \% \mathrm{Cl}$ & Reference \\
\hline $\begin{array}{l}3 \text { Mar - } 26 \text { Sep } \\
2011\end{array}$ & 14 Jun 2011 & $\# 1$ & $17.8 \%$ & $\begin{array}{l}16.2 \%- \\
19.4 \%\end{array}$ & [21] \\
\hline $\begin{array}{l}1 \mathrm{Jul}-31 \mathrm{Dec} \\
2011\end{array}$ & 30 Sep 2011 & \#108 & $21.6 \%$ & $\begin{array}{l}19.8 \%- \\
23.4 \%\end{array}$ & [17] \\
\hline $\begin{array}{l}\text { 1 Sep - } 31 \text { Dec } \\
2015\end{array}$ & 31 Oct 2015 & $\# 1600$ & $30.1 \%$ & $\begin{array}{l}25.1 \%- \\
35.6 \%\end{array}$ & [22] \\
\hline $\begin{array}{l}1 \mathrm{Jul}-31 \text { Aug } \\
2017\end{array}$ & 31 Jul 2015 & \#2239 & $37.9 \%$ & $\begin{array}{l}33.7 \%- \\
42.15\end{array}$ & [23] \\
\hline
\end{tabular}

Simulations using the computational model described in the previous section were conducted by varying the two unknown transmission probabilities and the prevalence of Day 1 . The combinations of the three variables used in the simulations are constructed based on 3-dimensional hypercube, varying the two transmission probabilities from $0-100 \%$ (with $0.1 \%$ increments) and the prevalence of Day 1 from 16.2$19.4 \%$ (with $0.1 \%$ increment). 33,066,033 simulations $(1,001 \times 1,001 \times 33)$ were conducted. Each simulation was conducted to simulate prevalence for 2,500 days where the prevalence rates reached equilibrium. 487 of the $33,066,033$ simulation generated results fitted within the $95 \%$ confidence interval of the four point-prevalence rate on their respective day. These 487 sets of parameters were used to further conduct simulations of interventions. Figure 2 illustrates simulation results of these 487 simulations.

Simulations of Interventions

Three types of intervention scenarios were evaluated using the computational model: (1) hand-hygiene compliance by HCWs, (2) screening-and-isolation upon all admission, and (3) implementing both interventions at the same time. Assuming interventions implemented on Day 2501, we simulated the long term impact of different hypothetical intervention scenarios on MRSA transmission dynamics. The 487 sets of parameters that fitted within $95 \% \mathrm{Cl}$ of the four point-prevalence rates were used as the input parameters for the computational model. Effects of interventions were evaluated by comparing the point prevalence of Day 2500 and Day 7500 for each of the simulations.

Intervention Scenario 1: Hand-Hygiene Compliance by HCWs

Hand-hygiene compliance by HCWs was simulated by reducing the average contamination duration $1 / \mu$. Five levels of hand-hygiene compliance by HCWs were evaluated by reducing the average contamination duration by $10 \%, 20 \%, 30 \%, 40 \%$ or $50 \%$. Computational model defined in the previous section was used to simulate effects of hand-hygiene by HCWs compliance to prevalence in our study. 2,435 simulations (5 Loading [MathJax]/jax/output/CommonHTML/jax.js s) were conducted for this scenario. 
The model was further extended in order to study effects of screening-and-isolation upon admission to prevalence rate. We assume a $100 \%$ screening success rate, a 5 -day isolation period, and a $100 \%$ decolonization rate after 5 days in isolation. An additional compartment was added in the model in order to represent the screening-and-isolation upon admission. All colonized admissions were put into an isolation compartment $\mathrm{I}$, and they were forwarded to compartment $\mathrm{U}$ after 5 days. Schematic of the extended model is illustrated in Fig. 3. 487 simulations were conducted for this scenario.

Intervention Scenario 3: Implementing Both Interventions at the Same Time

Simulation of intervention scenario 2 was run with five levels of hand-hygiene compliance by HCWs (reducing the average contamination duration by $10 \%, 20 \%, 30 \%, 40 \%$ or $50 \%$ ). 2,435 simulations were conducted for this scenario.

\section{Results}

Results of the 2,435 simulations in intervention scenario 1, hand-hygiene compliance for HCWs, are illustrated in Fig. 4 and summarized in Table 4 . It is further estimated that for every $10 \%$ reduction in average contamination duration, there is an average reduction of 1.29 percentage point in prevalence rate compared with the prevalence rate before the intervention was implemented.

Table 4

Effect of five levels of hand-hygiene compliance to MRSA colonization prevalence.

\begin{tabular}{|llll|}
\hline Hand-hygiene compliance level & $\begin{array}{l}\text { Average reduction in prevalence } \\
\text { (in percentage point) }\end{array}$ & $\begin{array}{l}\text { Standard } \\
\text { Deviation }\end{array}$ & $\begin{array}{l}95 \% \\
\text { C.I. }\end{array}$ \\
\hline $\begin{array}{l}10 \% \text { reduction in average } \\
\text { contamination duration for HCWs }\end{array}$ & 1.38 & 0.92 & $\begin{array}{l}1.30- \\
1.46\end{array}$ \\
$\begin{array}{l}20 \% \text { reduction in average } \\
\text { contamination duration for HCWs }\end{array}$ & 2.84 & 1.91 & $2.67-$ \\
$\begin{array}{l}30 \% \text { reduction in average } \\
\text { contamination duration for HCWs }\end{array}$ & 4.37 & 2.93 & $4.10-$ \\
\hline $\begin{array}{l}40 \% \text { reduction in average } \\
\text { contamination duration for HCWs }\end{array}$ & 5.91 & 3.62 \\
\hline $\begin{array}{l}50 \% \text { reduction in average } \\
\text { contamination duration for HCWs }\end{array}$ & 7.44 & & $5.56-$ \\
\hline
\end{tabular}

Results of the 487 simulations in intervention scenario 2, screening-and-isolation upon admission, are illustrated in Fig. 5. Our simulation results estimated that the screening-and-isolation intervention results in an average reduction of 19.04 percentage point in prevalence rate (s.d. $=1.58 ; 95 \% \mathrm{Cl}=18.90-19.18$ ) compared with the prevalence rate before the intervention was implemented. 
Results of the 2,435 simulations in intervention scenario 3, implementing both interventions at the same time, are illustrated in Fig. 6 and summarized in Table 5.

\section{Table 5}

Combined effect of hand-hygiene compliance and screening-and-isolation upon admission to MRSA colonization prevalence.

\begin{tabular}{|llll|}
\hline Hand-hygiene compliance level & $\begin{array}{l}\text { Average reduction in } \\
\text { prevalence }\end{array}$ & $\begin{array}{l}\text { Standard } \\
\text { Deviation }\end{array}$ & 95\% C.I. \\
\hline $\begin{array}{l}10 \% \text { reduction in average contamination } \\
\text { duration for HCWs }\end{array}$ & 21.99 & 0.65 & $\begin{array}{l}21.93- \\
22.05\end{array}$ \\
\hline $\begin{array}{l}20 \% \text { reduction in average contamination } \\
\text { duration for HCWs }\end{array}$ & 25.34 & 2.60 & $25.11-$ \\
\hline $\begin{array}{l}30 \% \text { reduction in average contamination } \\
\text { duration for HCWs }\end{array}$ & 28.31 & 4.14 & 25.57 \\
\hline $\begin{array}{l}40 \% \text { reduction in average contamination } \\
\text { duration for HCWs }\end{array}$ & 30.00 & 4.49 & $28.94-$ \\
\hline $\begin{array}{l}50 \% \text { reduction in average contamination } \\
\text { duration for HCWs }\end{array}$ & 30.94 & 4.44 & $29.60-$ \\
\hline
\end{tabular}

\section{Discussion}

Close contact is the major transmission route of MRSA infections. The primary considerations in this study are how to represent the heterogeneity of contact mixing between residents and HCWs in the model, and the availability of social contact matrix data for parameters estimation. The modeling framework of this study employed explicit representation of the heterogeneous contact mixing between residents and $\mathrm{HCWs}$. The contact parameters of this study were estimated based on the results of a nursing home survey conducted to residents and HCWs of 53 nursing homes. These approaches provide more legitimate simulation results of MRSA transmission in nursing homes. The model and methodology of this study also provide an instantaneous framework to evaluate hypothetical scenarios and to conduct "what-if" analyses. Nursing home administrators can employ the methodology of our study to make informed judgement and decision on infection control strategies accordingly.

Our simulation results suggest that the two simulated interventions, (1) hand-hygiene compliance for HCWs and (2) screening-and-isolation upon admission, are effective in driving down MRSA colonization prevalence. Quantitative data shows that every $10 \%$ reduction in average contamination duration for $\mathrm{HCW}$ s results in a reduction of 1.29 percentage points in prevalence on average. The screening-andisolation upon admission intervention is also shown to be effective in driving prevalence down, with a 19.04 percentage point reduction on average. In intervention scenario 3 , the magnitude of intervention effect in prevalence reduction is larger than the sum of the magnitude of intervention of scenario 1 and 2 . This synergistic effects observed by implementing both interventions together in scenario 3 is quite oncouranina Thic rocult chauld ho hrounaht to broader attention as hand-hygiene based intervention is Loading [MathJax]/jax/output/CommonHTML/jax.js 
relatively easy and cheap to be implemented and is shown to be effective in bringing down MRSA colonization prevalence. Our simulation results provide quantitative data for nursing home administrators in interventions planning, design, adjustment, effect estimation and comparison.

Hand-hygiene intervention in health-care settings is beyond merely providing hand-hygiene facilities and implementing policy for HCWs. Prior study [24] reported that a one-hour lecture plus 30-minute hand-on session could effectively improve the hand-hygiene compliance from 9.3-30.4\%. The World Health Organization (WHO) published guidelines in 2009 for implementing and evaluating hand hygiene programmes in healthcare settings [25]. The guidelines had identified five components to be implemented in healthcare-setting, including (1) using soap and water or alcohol-based hand rub at point of care or carried by the HCWs, (2) training and education, (3) observation and performance feedback, (4) reminders, and (5) administrative support/institutional safety climate. A recent systematic review reported that multimodal interventions that include some or all strategies recommended in the WHO guidelines might slightly improve hand hygiene compliance [26]. As to screening-and-isolation, though it was advocated by many researchers $[27,28]$, studies in nursing homes were limited but some studies reported the effectiveness of such measure in hospital settings [29, 30].

\section{Conclusion}

We presented a computational model with heterogeneous social contact mixing to simulate the transmission of MRSA in nursing homes. This approach can be used to conduct scenario analyses for MRSA transmission in nursing homes, and can also be generalized to other setting including hospitals and households as well as multi-drug resistance organisms such as Extended spectrum beta-lactamases and Carbapenem-resistant enterobacteriaceae. Several limitations of the study are noteworthy. First, the potential super-spreading events and transmissibility variation in individual or sub-groups were not considered in this model. Second, this study mainly employed the survey data of nursing homes in Hong Kong to parameterize the model. Region or country specific data including point prevalence, characteristics of nursing home and social mixing matrix is needed to study the situations in different countries/regions. Finally, we are not aware of any prior study about the efficacy of MRSA screening and decolonization of nursing homes and $100 \%$ efficacy was assumed in this study. Further study is needed to parameterize these two factors.

\section{Abbreviations}

AMR

Antimicrobial resistance

$\mathrm{Cl}$

Confidence Interval

HCW

Health-care worker 
Methicillin-resistant staphylococcus aureus

sd

Standard deviation

WHO

World Health Organization

\section{Declarations}

\section{Ethical Approval and Consent to Participate}

Not applicable.

\section{Consent for Publication}

Not applicable.

\section{Availability of Data and Material}

Not applicable.

\section{Competing Interests}

The authors declare that they have no competing interests.

\section{Funding}

This paper was solely supported by Sungkyun Research Fund, Sungkyunkwan University, 2019 (S-20182558-000-01).

\section{Author's Contributions}

Authors contributions are as follows: (i) Conceptualization - all authors; (ii) Methodology - AT and KOK; (iii) Model implementation - AT and KOK; (iv) Formal analysis - AT, KOK, VW and WT; (iv) Writing (drafting, reviewing and editing) - all authors.

\section{Acknowledgement}


Arthur Tang (AT) acknowledges supported by Sungkyun Research Fund, Sungkyunkwan University, 2019 (S-2018-2558-000-01). Kin On Kwok (KOK) acknowledges Health and Medical Research Fund of the Health, Welfare and Food Bureau of the Hong Kong SAR Government (grant nos. CU-17-C18), Wellcome Trust (200861/Z/16/Z) and Li Ka Shing Institute of Health Sciences.

\section{References}

1. US Centers for Disease Control and Prevention. Biggest Threats and Data - Antibiotic/Antimicrobial Resistance (AR/AMR). Available from: https://www.cdc.gov/drugresistance/biggest_threats.html. Accessed August 3, 2020.

2. Bradley SF. Methicillin-resistant Staphylococcus aureus in nursing homes. Epidemiology, prevention and management. Drugs Aging. 1997;10(3):185-98.

3. O'Sullivan NR, Keane CT. The prevalence of methicillin-resistant staphylococcus aureus among the residents of six nursing homes for the elderly. J Hosp Infect. 2000;45(4):322-9.

4. Wong JW, Ip M, Tang A, Wei VW, Wong SY, Riley S, Read JM, Kwok KO. Prevalence and risk factors of community-associated methicillin-resistant Staphylococcus aureus carriage in Asia-Pacific region from 2000 to 2016: a systematic review and meta-analysis. Clin Epidemiol. 2018;10:1489-501.

5. Boucher HW, Corey GR. Epidemiology of methicillin-resistant Staphylococcus aureus. Clin Infect Dis, 2008. 46 Suppl 5: p. S344-9. 3.

6. Chamchod F, Ruan S. Modeling the spread of methicillin-resistant Staphylococcus aureus in nursing homes for elderly. PLoS One. 2012;7(1):e29757.

7. Datta R, Huang SS. Risk of infection and death due to methicillin-resistant Staphylococcus aureus in long-term carriers. Clin Infect Dis. 2008;47(2):176-81.

8. Hawkins $\mathrm{G}$, et al. Should healthcare workers be screened routinely for meticillin-resistant Staphylococcus aureus? A review of the evidence. J Hosp Infect. 2011;77(4):285-9.

9. Garazi M, Edwards B, Caccavale D, Auerbach C, Wolf-Klein G. Nursing homes as reservoirs of MRSA: myth or reality? J Am Med Dir Assoc. 2009;10(6):414-8.

10. Mody L, Kauffman CA, Donabedian S, Zervos M, Bradley SF. Epidemiology of Staphylococcus aureus colonization in nursing home residents. Clin Infect Dis. 2008;46(9):1368-73.

11. Reynolds C, Quan V, Kim D, Peterson E, Dunn J, Whealon M, Terpstra L, Meyers H, Cheung M, Lee B, et al. Methicillinresistant Staphylococcus aureus (MRSA) carriage in 10 nursing homes in Orange County, California. Infect Control Hosp Epidemiol. 2011;32(1):91-3.

12. Bradley SF, Terpenning MS, Ramsey MA, Zarins LT, Jorgensen KA, Sottile WS, Schaberg DR, Kauffman CA. Methicillinresistant Staphylococcus aureus: colonization and infection in a long-term care facility. Ann Intern Med. 1991;115(6):417-22.

13. Sanford MD, Widmer AF, Bale MJ, Jones RN, Wenzel RP. Efficient detection and long-term persistence of the carriage of methicillin-resistant Staphylococcus aureus. Clin Infect Dis. 1994;19(6):1123-8. 
14. Hong Kong Centre for Health Protection. Methicillin-resistant Staphylococcus Aureus (MRSA) Infection. Available from: https://www.chp.gov.hk/en/healthtopics/content/24/10688.html. Accessed: August 3, 2020.

15. Kwok KO, Read JM, Tang A, Chen H, Riley S, Kam KM. A systematic review of transmission dynamic studies of methicillin-resistant Staphylococcus aureus in non-hospital residential facilities. BMC Infect Dis. 2018;18(1):188.

16. Kwok KO, Chan H, Wei VWI, Tang A, Riley S. A longitudinal contact survey in residential care homes for the elderly in Hong Kong. (In preparation).

17. Cheng VC, Tai JW, Wong ZS, Chen JH, Pan KB, Hai Y, et al. Transmission of methicillin-resistant Staphylococcus aureus in the long term care facilities in Hong Kong. BMC Infect Dis. 2013;13:205.

18. Shenoy ES, Paras ML, Noubary F, Walensky RP, Hooper DC. Natural history of colonization with methicillin-resistant Staphylococcus aureus (MRSA) and vancomycin-resistant Enterococcus (VRE): a systematic review. BMC Infect Dis. 2014;14:177.

19. Kwok CL, Lee CKM, Lo WTL, Yip PSF. The Contribution of Ageing to Hospitalisation Days in Hong Kong: A Decomposition Analysis. Int J Health Policy Manag. 2017;6(3):155-64.

20. Pineles L, Morgan DJ, Lydecker A, Johnson JK, Sorkin JD, Langenberg P, et al. Transmission of methicillin-resistant Staphylococcus aureus to health care worker gowns and gloves during care of residents in Veterans Affairs nursing homes. Am J Infect Control. 2017;45(9):947-53.

21. Kwok KO, Wei VWI, Yu CH, Hsu EK, Lee SS, Chen H. Prevalence of methicillin-resistant staphylococcus aureus in residential care homes for the elderly in Hong Kong: insight on facility-level Infection risk profile. (In preparation).

22. Cheng VCC, Chen H, Wong SC, Chen JHK, Ng WC, So SYC, et al. Role of Hand Hygiene Ambassador and Implementation of Directly Observed Hand Hygiene Among Residents in Residential Care Homes for the Elderly in Hong Kong. Infect Control Hosp Epidemiol. 2018;39(5):571-7.

23. Chen H, Au KM, Hsu KE, Lai CK, Myint J, Mak YF, et al. Multidrug-resistant organism carriage among residents from residential care homes for the elderly in Hong Kong: a prevalence survey with stratified cluster sampling. Hong Kong Med J. 2018;24(4):350-60.

24. Huang TT, Wu SC. Evaluation of a training programme on knowledge and compliance of nurse assistants' hand hygiene in nursing homes. J Hosp Infect. 2010;68(2):164-70.

25. World Health Organization. (2009) World Health Organization Guidelines on Hand Hygiene in Health Care. First Global Patient Safety Challenge Clean Care is Safer Care. Available at https://www.who.int/gpsc/5may/tools/en/. Accessed 31st July 2020.

26. Gould DJ, Moralejo D, Drey N, Chudleigh JH, Taljaard M. Interventions to improve hand hygiene compliance in patient care. Cochrane Database of Systematic Reviews, 2017. Issue 9. Art. No.: CD005186.

27. Boyce JM, Havill NL, Kohan C, Dumigan DG, Ligi CE. Do infection control measures work for methicillin-resistant Staphylococcus aureus? Infect Control Hosp Epidemiol. 2004;25:395-401. 
28. Verbrugh HA. Value of screening and isolation for control of methicillin-resistant Staphylococcus aureus. Clin Infect Dis. 2005;41(2):268-71.

29. Ahmed MO, Elramalli AK, Amri SG, Abuzweda AR, Abouzeed YM. Isolation and screening of methicillin-resistant Staphylococcus aureus from health care workers in Libyan hospitals. East Mediterr Health J. 2012;18(1):37-42.

30. Popiel KY, Miller MA. Evaluation of vancomycin-resistant enterococci (VRE)-associated morbidity following relaxation of VRE screening and isolation precautions in a tertiary care hospital. Infect Control Hosp Epidemiol. 2014;35(7):818-25.

\section{Figures}

Admission

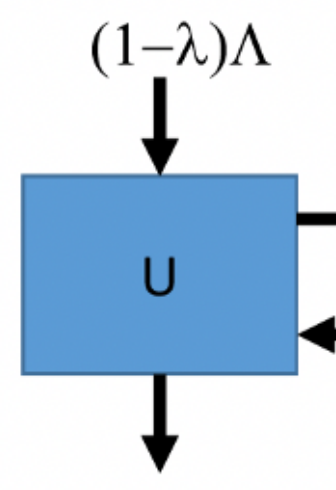

$\gamma_{u} \mathrm{U}$

Discharge / Death
Admission

Transmission $\beta_{\mathrm{r}} \mathrm{UC} / \mathrm{N}_{\mathrm{r}}+\beta_{\mathrm{h}} \mathrm{UH}_{\mathrm{c}} / \mathrm{N}_{\mathrm{h}}$

\section{$\omega \mathrm{C}$}

Decolonization

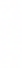




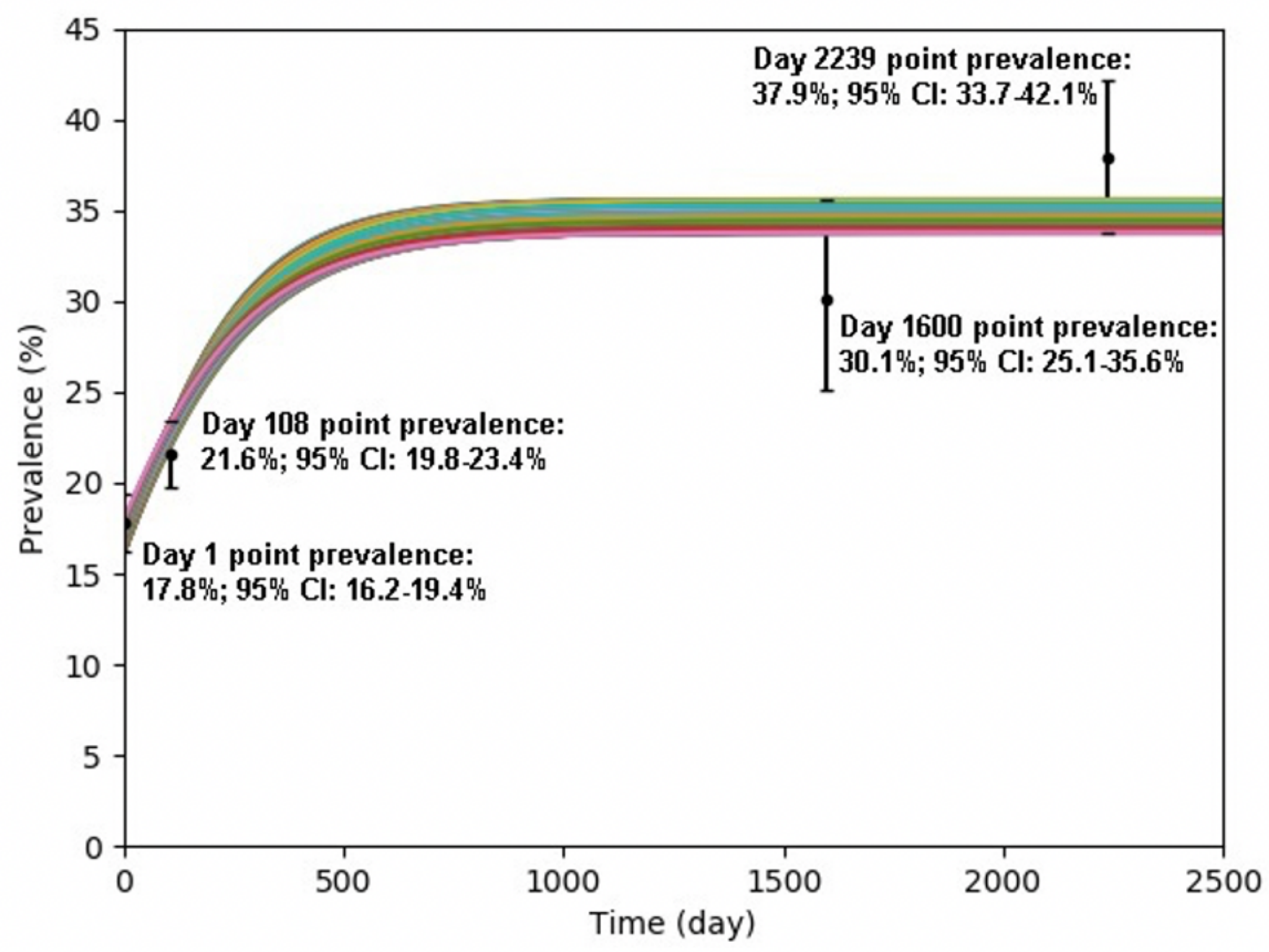

Figure 2

Plot of 487 simulation results that fitted within $95 \% \mathrm{Cl}$ of the four point-prevalence rates on their respective day. 


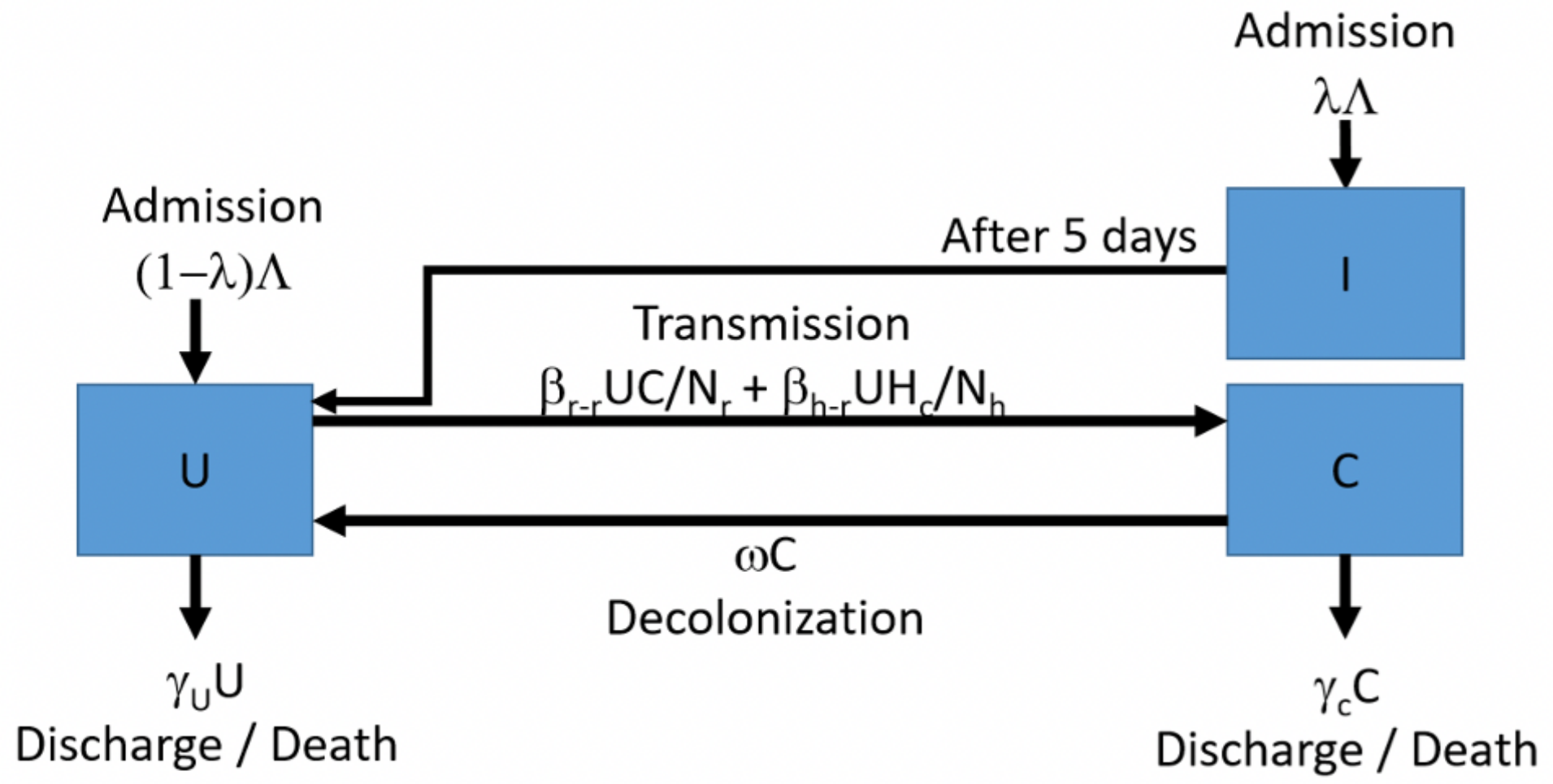

Contamination

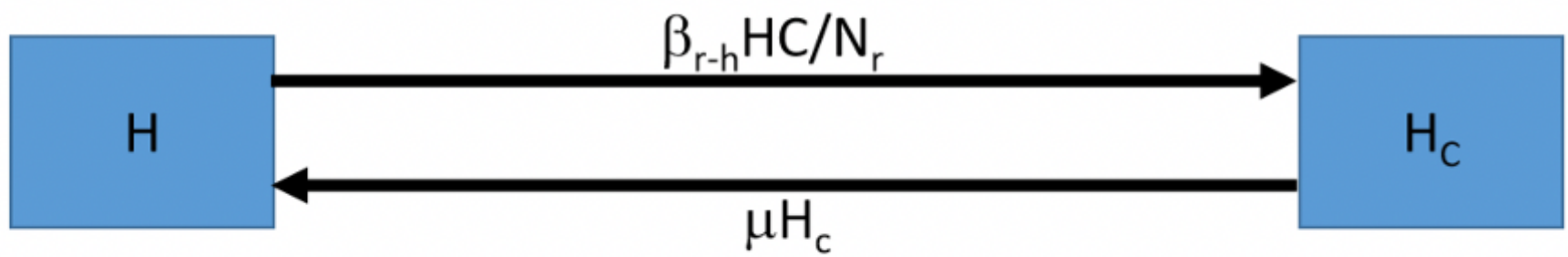

Decontamination

Figure 3

Schematic of the extended model for screening-and-isolation upon admission. 

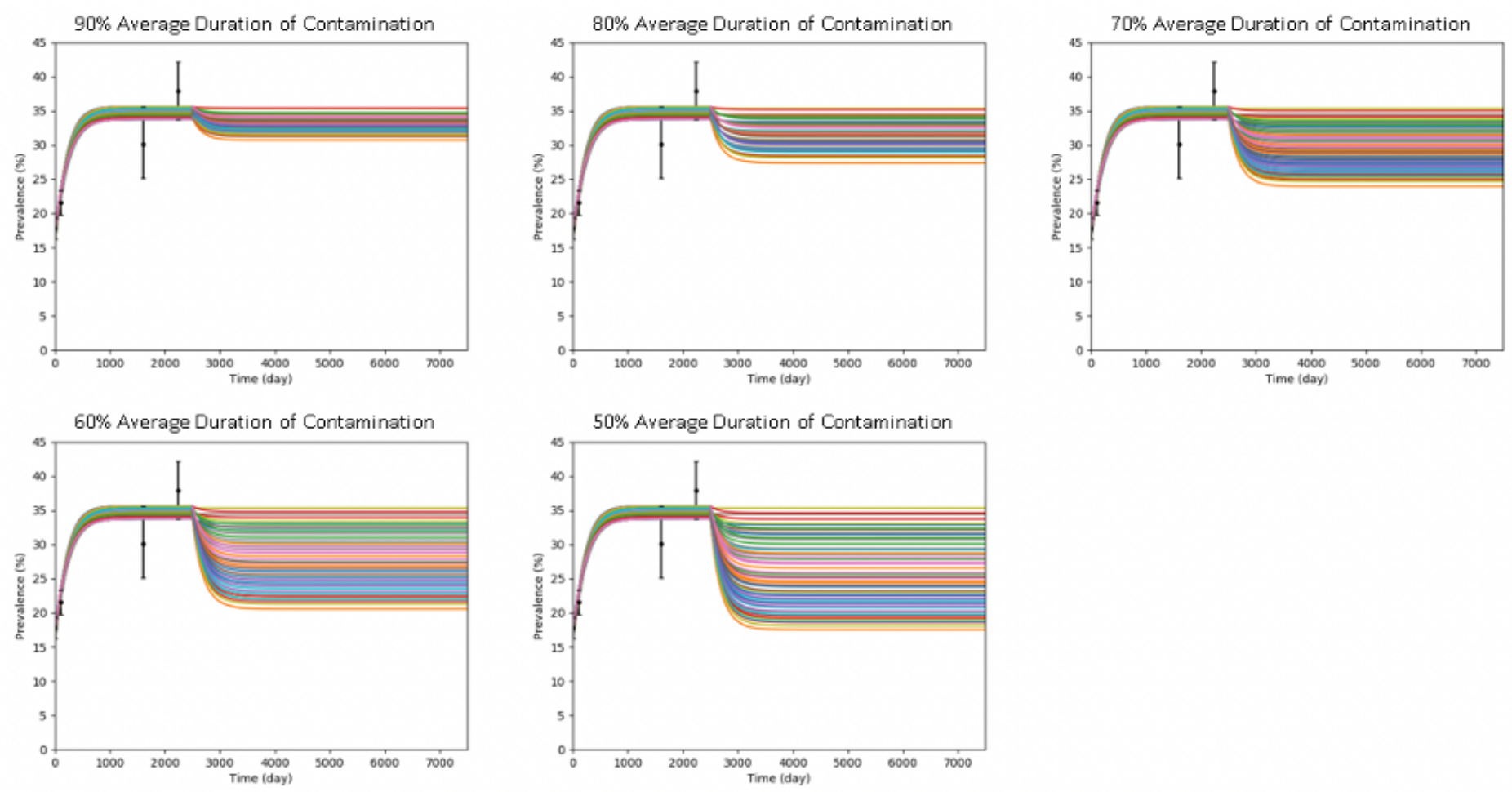

\section{Figure 4}

Plots of effect of five levels of hand-hygiene compliance to MRSA colonization prevalence. Hand-hygiene compliance interventions were implemented on Day 2501. 


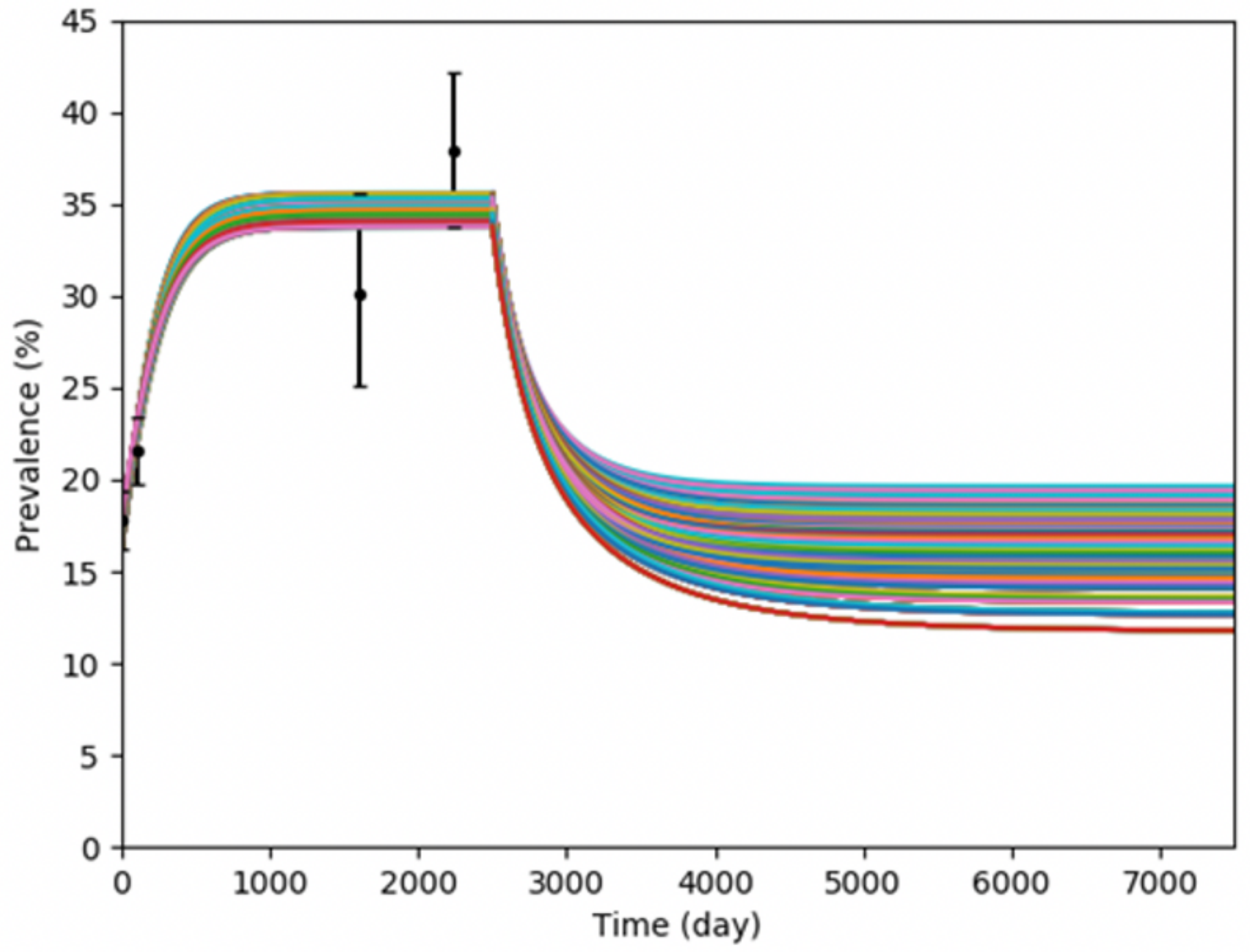

Figure 5

Plot of effect of screening-and-isolation upon admission to MRSA colonization prevalence. 

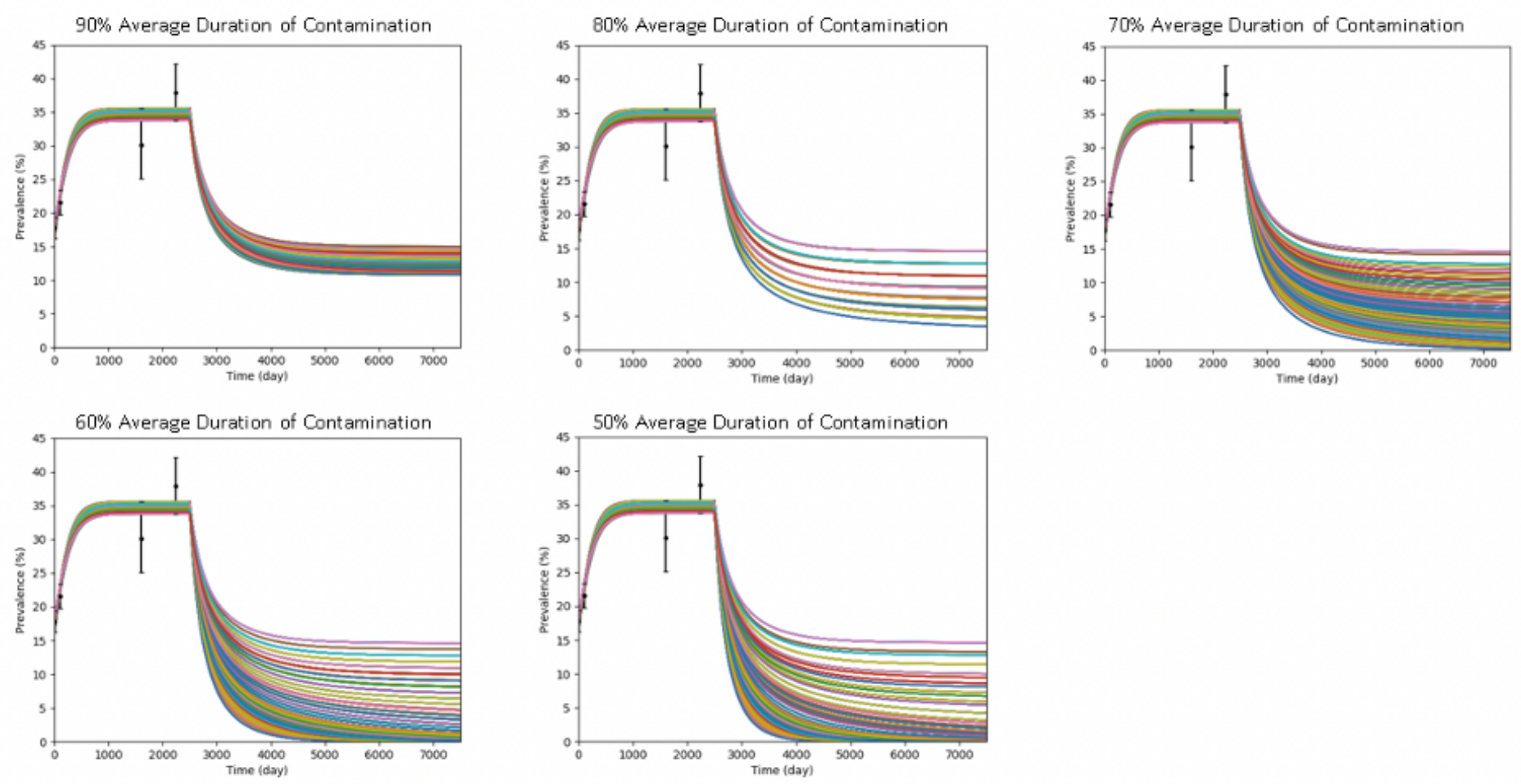

Figure 6

Plots of combined effect of hand-hygiene compliance and screening-and-isolation upon admission to MRSA colonization prevalence. Interventions were implemented on Day 2500. 